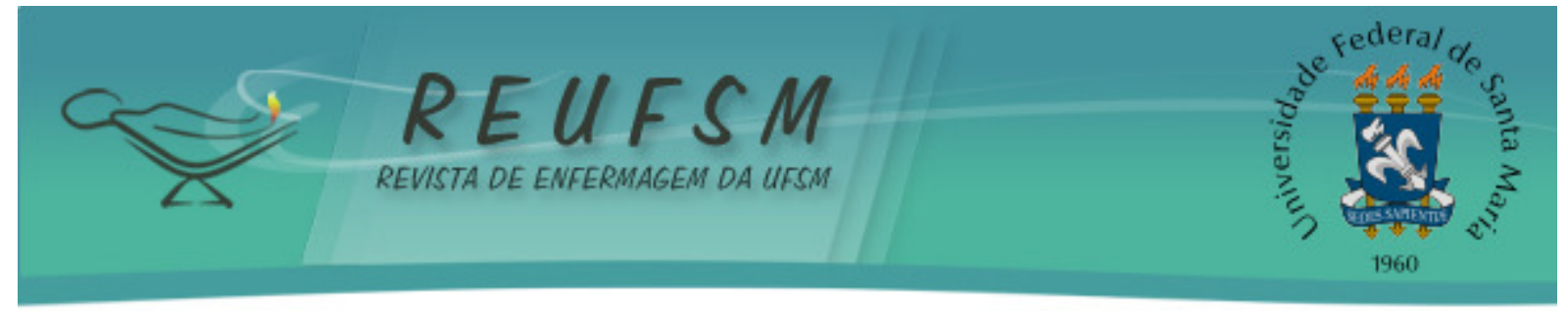

ARTIGO ORIGINAL

\title{
TRABALHO EM EQUIPE/PROXIMIDADE DO PACIENTE: ELEMENTOS DA PRÁXIS DE ENFERMEIRAS NA TERAPIA INTENSIVA
}

\author{
TEAMWORK/CLOSENESS TO PATIENT AS ELEMENTS OF PRAXIS OF NURSES IN INTENSIVE \\ CARE
}

\section{TRABAJO EN EQUIPOIPROXIMIDAD CON EL PACIENTE: ELEMENTOS DE LA PRAXIS DE ENFERMERAS DE CUIDADOS INTENSIVOS}

Gustavo de Mello Duarte ${ }^{1}$ Marcelo da Silva Alves ${ }^{2}$

Doi: $10.5902 / 217976929059$

RESUMO: Objetivo: desvelar a práxis de enfermeiros que atuam em unidades de terapia intensiva. Método: pesquisa qualitativa que utilizou a Sociologia do cotidiano e a conceituação de Karel Kosic para práxis como alicerces teóricos. Realizado através de entrevista semiestruturada com oito enfermeiros de unidades de terapia intensiva de um hospital filantrópico da Zona da Mata de Minas Gerais no período de janeiro a abril de 2012. Os dados foram analisados por triangulação entre categorias, referencial e a vivência do pesquisador. Resultados: constatou-se que com trabalho em equipe os enfermeiros reconhecem seu próprio papel e de outros profissionais, bem como tem seu trabalho respeitado e valorizado. Do mesmo modo, o estar próximo dos pacientes ajuda na criação de vínculos e no atendimento adequado das necessidades destes. Considerações Finais: ambos os fatores resgatam valores primordiais a enfermagem, auxiliando em todo o processo de trabalho dos enfermeiros e agregando valores humanísticos a este.

Descritores: Enfermagem; Terapia intensiva; Equipe de enfermagem; Relações enfermeiro-paciente.

ABSTRACT: Aim: to unveil the practice of nurses working in intensive care units. Method: a qualitative study that used the sociology of everyday life and the concept of praxis as Karel Kosic to theoretical foundations. It was conducted through semi-structured interviews with eight nurses from the intensive care unit of a hospital's philanthropic "Zona da Mata" of Minas Gerais (Brazil) in the period of January to April 2012. Data were analyzed by triangulation between categories, reference and experience of the researcher. Results: it was found that with teamwork nurses recognize their own role and other professionals as well as have their work recognized and valued. Therefore, being next to patients helps on creating bonds and meeting patients' needs adequately. Final Thoughts : both factors rescue primordial values nursing assisting in the process of nurses' work and adding to this humanistic values .

Descriptores: Nursing; Intensive care; Nursing team; Nurse-patient relations.

RESUMEN: Objetivo: conocer la práctica de las enfermeras que trabajan en las unidades de cuidados intensivos. Método: investigación cualitativa que utilizó la Sociología del cotidiano y la conceptuación de Karel Kosic para praxis como fundamentos teóricos. Realizado a través de entrevistas semiestructuradas con ocho enfermeras de un hospital filantrópico de Zona da Mata de Minas Gerais (Brasil) en Enero-Abril de 2012. Los datos fueron analizados por triangulación entre las

\footnotetext{
${ }^{1}$ Enfermeiro; Mestre em Enfermagem pela Universidade Federal de Juiz de Fora (UFJF); Juiz de Fora, Minas Gerais, Brasil. enfergustaduarte@gmail.com

2 Enfermeiro; Doutor em Saúde Coletiva pelo IMS da Universidade do Estado do Rio de Janeiro; Professor Associado da Faculdade de Enfermagem da UFJF; Juiz de Fora; Minas Gerais; Brasil. enfermar@oi.com.br
} 


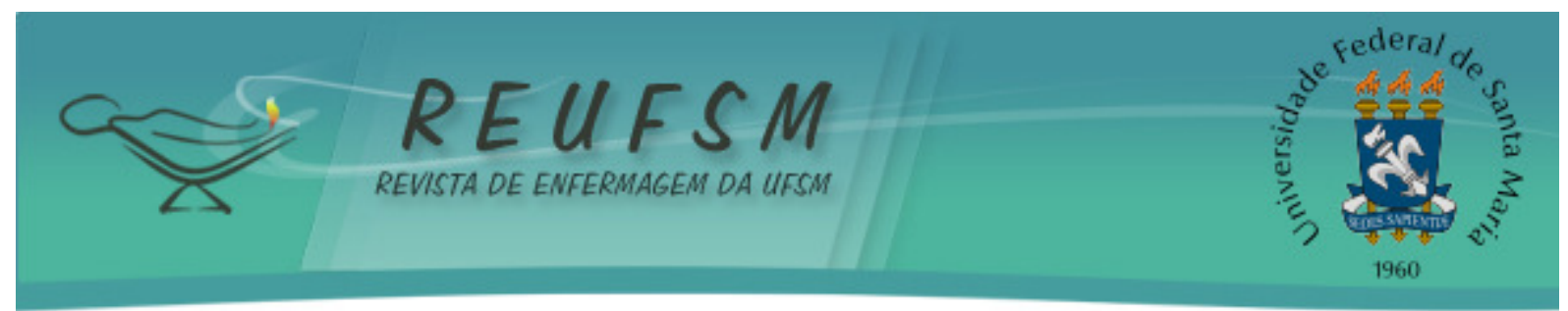

categorías, fundamentos teóricos y la experiencia del investigador. Resultados: se constató que con el trabajo en equipo las enfermeras reconocen su propio papel y de otros profesionales, así como tener su trabajo reconocido y valorado. Del mismo modo, estar próximo de los pacientes ayuda en la creación de vínculos y en el atendimiento adecuado a las necesidades de estos. Consideraciones finales: Ambos factores recuperan valores primordiales de enfermería, ayudando en el proceso de trabajo y la adición valores humanistas.

Descritores: Enfermería; Terapia intensiva; Grupo de enfermería; Relaciones enfermeropaciente.

\section{INTRODUÇÃO}

As atuais unidades de terapia intensiva (UTI) são vistas e consideradas como o último recurso para se restituir a vida de pessoas que têm sua saúde comprometida por agravos de múltiplas naturezas. ${ }^{1}$ Esta visão é originada pela complexa estrutura que alicerça esses ambientes e suas atividades de assistência a essas pessoas, bem como pelas enfermidades ali atendidas.

A complexidade dessa estrutura é diretamente proporcional à gravidade das enfermidades e das situações de risco à vida das pessoas que necessitam estar em uma UTI. Esta é a responsável pelo atendimento das mais complexas, graves e urgentes situações que exigem a intervenção de muitos profissionais - dentre eles, os de enfermagem. ${ }^{2}$

Logo, mediante essas necessidades, as UTIs são locais que se instrumentalizaram de um grande aparato tecnológico e mecânico que sustenta e auxilia muitas das atividades profissionais ali desenvolvidas. ${ }^{3}$ São aparelhos como ventiladores artificiais, bombas infusoras, monitores multiparâmetros, máquinas de substituição da função renal, entre muitas outras.

Do mesmo modo, técnicas, procedimentos e conhecimentos técnico-científicos dos mais modernos e atuais são empregados no ambiente da unidade de terapia intensiva e, quando se somam a todo o aparato material existente, constituem a capacidade destas unidades de salvarem vidas - o que origina a visão mencionada no início do texto. ${ }^{4}$

Nesse contexto, a unidade de terapia intensiva torna-se um ambiente pleno de experiências e situações que permeiam o cotidiano dos profissionais de enfermagem no qual estão inseridos ininterruptamente nas 24 horas do dia. E é a vivência desse rico cotidiano, repleto de possibilidades, que torna importante o estudo desse ambiente e dos profissionais de enfermagem ali inseridos.

0 estudo e a compreensão desse dia a dia podem se configurar em importantes fomentadores de informações para a melhoria da enfermagem como profissão, do desenvolver das atividades dos enfermeiros que trabalham com terapia intensiva, bem como para transformar e adequar esse cotidiano em suas deficiências.

O entendimento do que é Práxis passa por inúmeros conceitos que, no decorrer do tempo, vêm sofrendo alterações de acordo com suas aplicabilidades e correntes de pensamento que os formulam. Com origem no pensamento grego, ganhou notoriedade com as postulações teórico-filosóficas de Karl Marx. Assim, a aplicabilidade deste conceito pode ser vista em estudos de naturezas e finalidades variadas. ${ }^{5}$

Muito comumente está associado ao significado de prática, mas esta é uma conceituação muito restrita. Em sua conceituação inicial, na Grécia, ultrapassava o sentido de uma simples prática, pois levava em consideração o conhecimento e a moral de cada um. $^{6}$ Da mesma forma, pode ser conceituada com sendo o emprego de conhecimentos teóricos em um fazer, ou seja, a junção entre estas duas dimensões. ${ }^{5}$

Contudo, nesta pesquisa, adotou-se outro sentido, para entendimento da proposta feita e dos resultados apresentados, pensa-se a Práxis como sendo os significados que uma prática assume para aquelas pessoas que a desempenham. ${ }^{7}$ Sob esta ótica, a Práxis assume 


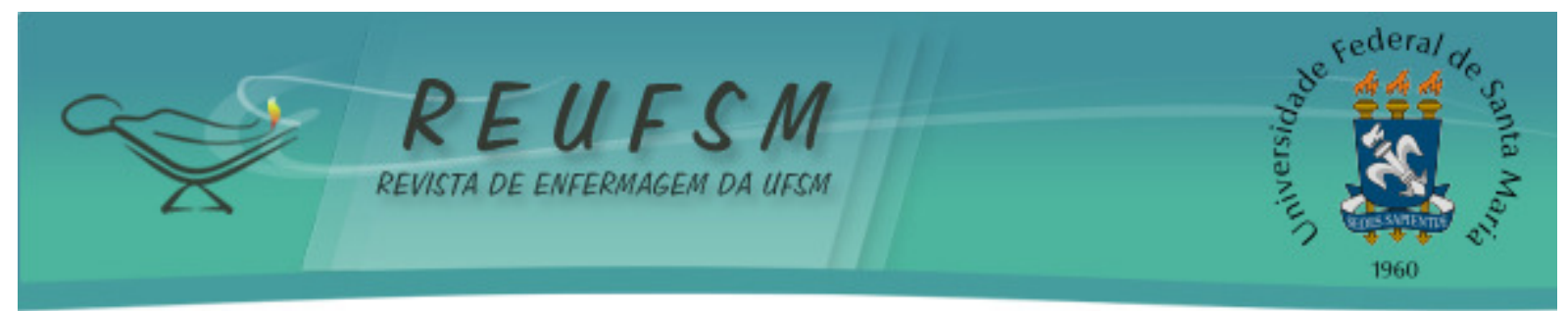

um aspecto mais amplo e diferenciado porque suscita, de cada um, uma reflexão, uma conscientização e uma significação do papel que se desempenha.

Estuda-la sob esta conceituação e poder lançar um olhar sobre a realidade do vivido cotidiano dos profissionais de enfermagem é ver com os olhos dessas pessoas, entendendo não como as coisas deveriam ser, mas como elas realmente são. Pode-se obter com este olhar um maior embasamento da realidade de toda uma profissão. É a oportunidade de observar a dialética que existe do quem faz e de por que faz.

Segundo os referenciais adotados, o ser humano, perante sua realidade, não se porta de forma alheia, mas sim proativa, agindo mediante seus interesses e necessidades. ${ }^{7 .}$ ${ }^{8}$ Logo, inserido concretamente em sua realidade, tem experiências úteis que the permitem criar sua própria representação das coisas que o cercam.

A Práxis de ser enfermeiro no cotidiano de uma unidade de terapia intensiva remete ao que significa para esse profissional todas as suas funções, fazeres e atuações dentro desse ambiente: o que dá sentido ao seu papel profissional; o que, sob sua visão e reflexão, significa seu trabalho como enfermeiro de uma UTI, setor de trabalho tão complexo e repleto de vivências e experiências.

Assim, mediante toda a riqueza e a complexidade das unidades de terapia intensiva e da importância do estudo destas significações, quais seriam os elementos com relevância para serem formadores da Práxis de enfermeiros que atuam em UTI? Que aspectos do viver cotidiano desse ambiente ganham, aos olhos desses profissionais, importância para serem constituintes de suas definições profissionais?

0 presente estudo objetiva desvelar a Práxis de enfermeiros que atuam em unidades de terapia intensiva, pois desvelar os elementos do cotidiano profissional que, sob a percepção de enfermeiros que atuam em UTI, ganham significado diferenciado para serem constituintes desta. E tem sua significância justificada por todo o crescimento que o estudo destes conceitos, pautada na realidade profissional pode trazer a estas profissionais e à enfermagem como profissão.

\section{MÉTODO}

O estudo é uma pesquisa qualitativa que utilizou a Sociologia do Cotidiano e suas conceituações de pós-modernidade e de cotidiano como referencial teórico primário para análise dos dados. ${ }^{9}$ Por se tratar de um pensamento que propicia uma visão mais contextualizada e sensível a todas as nuances de um cenário social, foi o instrumento ideal para as pretensões deste estudo.

Utilizaram-se como campo de pesquisa três unidades de terapia intensiva de um hospital filantrópico de médio porte de um município da Zona da Mata de Minas Gerais: uma UTI geral, uma cardíaca e outra cirúrgica. Esta configuração permitiu uma diversidade de cenários, evitando possível viés na pesquisa e a saturação prematura dos dados.

Os sujeitos pesquisados eram profissionais de enfermagem com nível superior que, no período de realização da pesquisa, trabalhavam nas referidas unidades. De um universo de doze profissionais, três se recusaram a participar da pesquisa, um não pôde ser contatado, pois estava de férias. Logo, a pesquisa contou com oito participantes: cinco mulheres e três homens, com idades entre 25 e 45 anos e tempo de experiência em UTI entre cinco meses e 18 anos. A predominância de mulheres foi o motivo da adoção preponderante do gênero feminino nos textos referentes aos resultados da pesquisa.

0 critério de inclusão adotado foi o profissional estar atuando em uma das unidades de terapia intensiva da instituição. Foram oferecidas aos enfermeiros três possibilidades para a realização das entrevistas, em sua própria residência, em um local neutro, como uma lanchonete e, por fim, a critério do participante. Todos os oito participantes escolheram que as entrevistas fossem realizadas em seus horários de 


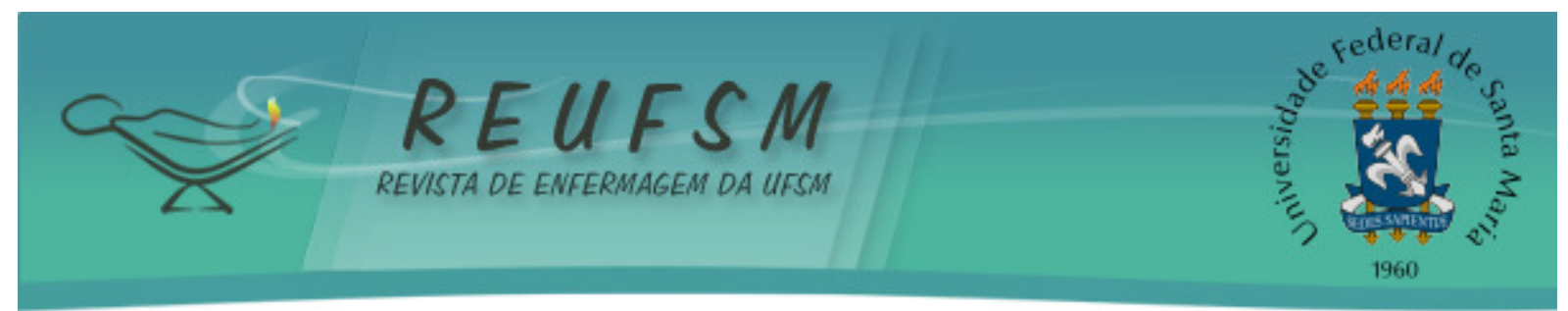

trabalho. Assim, para não interferir em suas atividades profissionais as entrevistas foram realizadas ou durante o horário destinado ao descanso e refeição, ou após a passagem de plantão, todas em sala destinada ao repouso dos profissionais com privacidade e sigilo.

Após aprovação em Comitê de Ética em Pesquisa com Seres Humanos (número 0004.1.471.000-11 deferido em 13 de dezembro de 2011) e da assinatura do Termo de Consentimento Livre e Esclarecido pelos participantes, em respeito às legislações vigentes, iniciou-se a coleta de dados. Utilizou-se entrevista semiestruturada como instrumento de coleta de dados. ${ }^{10}$ As entrevistas, gravadas em formato digital, foram transcritas e categorizadas segundo as similaridades e as relevâncias das temáticas apontadas pelas falas.

A partir de então, iniciou-se o processo indutivo de análise, confrontando os materiais empíricos (obtidos nas entrevistas e categorizados) com os referenciais teóricos adotados para o trabalho, juntamente com os conhecimentos do pesquisador. Esta técnica é conhecida como triangulação dos dados e busca atingir o ápice da descrição, explicação e compreensão, considerando a relação entre o fenômeno estudado e todas as variáveis que o influenciam. ${ }^{10-11}$

\section{RESULTADOS E DISCUSSÃO}

Os depoimentos das entrevistadas revelaram quatro elementos como sendo constituintes da Práxis do ser enfermeira no cotidiano da unidade de terapia intensiva. Contudo, devido à sua magnitude em tamanho e complexidade, esses elementos foram divididos em dois grupos por similaridades. Aqui se apresenta um desses grupos, formado pelo trabalho em equipe e pela proximidade com o paciente.

\section{0 trabalho em equipe}

Um breve olhar sobre a história da enfermagem desde seu estabelecimento como profissão já é suficiente para demonstrar que o trabalho em equipe é inerente ao estabelecimento da enfermagem pós-Florence. Empiricamente, é praticamente impossível pensar em uma enfermeira sem estar integrada a uma equipe. ${ }^{1}$

Este saber histórico, empírico, aqui ganha ares de cientificidade, pois, por meio das falas das entrevistadas, foi possível detectar que o trabalho em equipe é parte integrante do ser enfermeira na unidade de terapia intensiva. Assim sendo, é-lhe atribuída uma significância tal que esse elemento é parte integrante da Práxis dessas profissionais na UTI. O depoimento abaixo o exemplifica:

Olha, vou te dizer que eu gosto bem de trabalhar com as mesmas pessoas porque você vai conhecendo, vai vendo o jeito de cada um, você vai vendo os defeitos de cada um, você vai aprendendo a lidar com cada um melhor do que quando você cada hora você está com uma equipe; então, assim, eu gosto bem de trabalhar com um grupo mesmo fechado. E quando chega um novato, aí tem todo um processo de acolher [...]. (E5)

O trabalhar em equipe, na terapia intensiva, exige características sociais imprescindíveis, como coletividade, cooperação, compromisso e responsabilidade. Assim, características da UTI - como a alta complexidade dos cuidados, a mecanização e o grande volume de serviço - solicita que esse trabalhar em equipe seja harmonioso, que exista uma união entre as partes, e que toda a equipe esteja comprometida com as tarefas, transformando a UTI em um complexo ambiente social. ${ }^{1}$ 


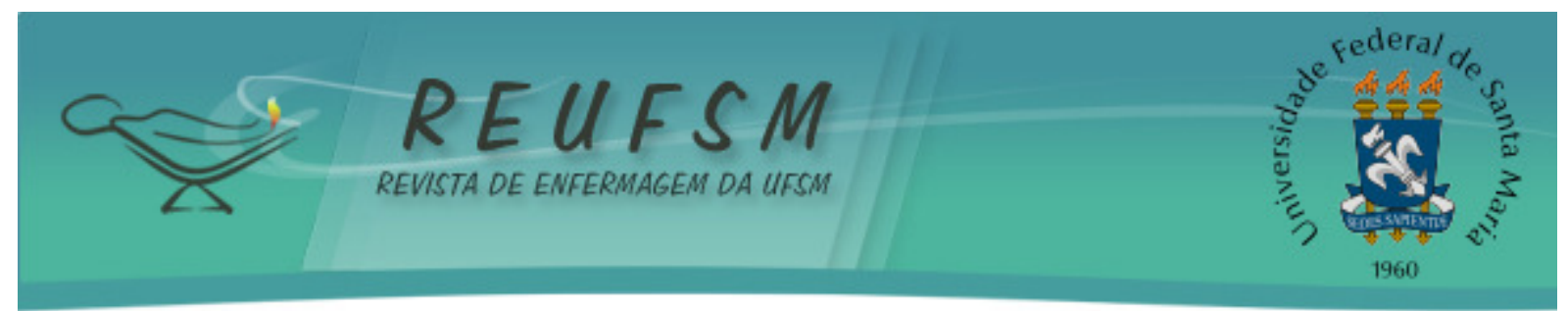

Percebe-se que a enfermeira, no vivido cotidiano de uma UTI, agrega à sua Práxis características que possibilitam que, em um ambiente complexo, mecanizado e repleto de sentimentos conflitantes, atributos de sociabilidade, harmonia e coletividade sejam colocados em prática, mesmo que de forma subjetiva. ${ }^{12}$

Dentro da própria equipe de enfermagem ou no âmbito do estafe multiprofissional, as enfermeiras de UTI conseguem trabalhar o senso de conjunto, conhecendo, reconhecendo e valorizando todos os membros que possam vir a ser componentes desta equipe. Isso demonstra que esse trabalhar em grupo tem relevância prática e abrange todas as relações sociais dentro da UTI. Esse fato é esclarecido pelos depoimentos abaixo:

[...] tenho uma abertura muito grande com os técnicos de enfermagem, com os psicólogos, com os fisioterapeutas; é, a gente na verdade tem um relacionamento muito aberto a questionamentos [...] a gente tem uma paridade muito grande, a equipe entende a posição do enfermeiro, aceita o enfermeiro como chefe da equipe [...]. (E6)

Equipe, ter senso de equipe, senso de equipe, eu coloco muito para os meus alunos, porque a gente trabalha com aluno, academia aí que eu mexo muito, pós-graduação e tal, que trabalhar em equipe não é só pensar em enfermagem como equipe não, é chamar o fisioterapeuta para responsabilidade dele, o médico, 0 fonoaudiólogo, psicólogo e tornar todo mundo parte daquele meio ali, daquela engrenagem, entendeu? (E3)

0 depoimento da entrevistada 6 ainda consegue mostrar outro aspecto desse trabalhar em grupo: é a condição de que a enfermeira, não só dentro da unidade de terapia intensiva, é a responsável por coordenar e chefiar o pessoal de enfermagem, assumindo a responsabilidade pelo perfeito funcionamento de toda e qualquer atividade que seja atribuída a esta. Esse fato capacita essas profissionais a falarem com propriedade do trabalhar em equipe. ${ }^{13}$

Por esse cenário, e porque as enfermeiras de UTI significam o trabalho em equipe a ponto de ser um fator constituinte de sua Práxis, elas conhecem as várias facetas desse elemento, pois são responsáveis como membros e como chefia destes conjuntos. Elas vivem o concreto e o real de ambas as situações, e tudo o que se pauta no concreto e no real é passível de credibilidade. ${ }^{9}$

\section{A proximidade com o paciente}

Da mesma forma que o trabalho em equipe, a proximidade com o paciente é inerente ao estabelecimento da enfermagem como profissão. Um olhar para a história e a constituição da enfermagem, bem como sobre seu foco de atuação, o cuidar, é suficiente para mostrar o quanto estar próximo das pessoas que dependem de cuidados é facilmente associado ao enfermeiro.

Por ser tratar de um setor fechado, onde a capacidade de ir e vir de ambas as partes estão limitadas os pacientes, por suas condições clínicas, e os profissionais, pelas necessidades do setor, como a constante observação dos pacientes, não é de se admirar que no ambiente da UTI esse elemento apareça como constituinte da práxis das enfermeiras que ali trabalham. ${ }^{2}$

Eu sempre visualizei trabalhar em Unidade de Terapia Intensiva olhando mais pelo cuidado que a gente presta, que é a oportunidade que a gente tem de ter um cuidado mais próximo do paciente, que muitas 


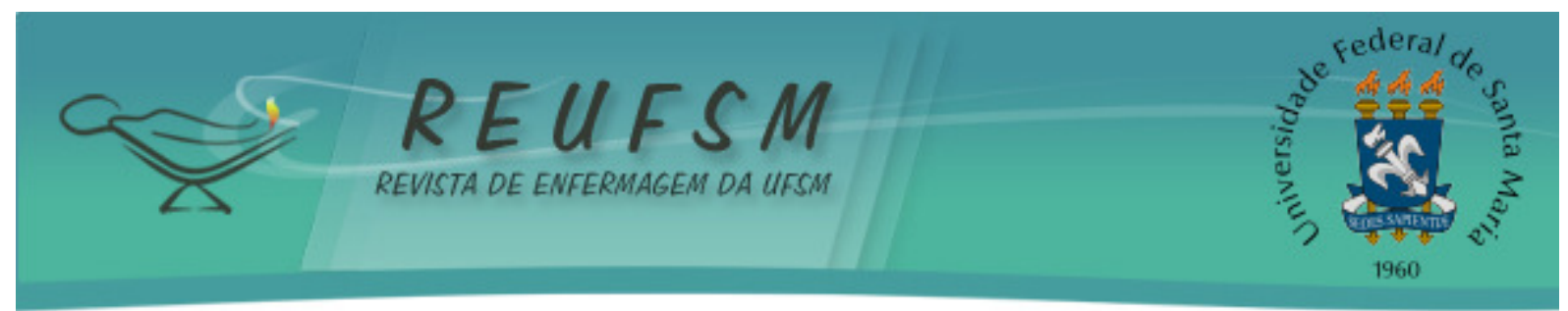

vezes você não tem tanta oportunidade quando você está em andares, eu acho que a gente acaba tendo um contato maior e, além disso, eu sempre tive o interesse de trabalhar com paciente crítico. (E7)

Assim, neste contexto, a UTI propicia a criação de vínculos entre essas duas partes que cotidianamente vivem e convivem juntas pelas 24 horas do dia, durante todo o tempo de permanência do paciente na unidade de terapia intensiva. Essa convivência, nem sempre harmoniosa, é necessária, pois consegue trazer ao profissional de enfermagem sentimentos de prazer e satisfação. ${ }^{2,13}$ Podemos vê-lo nos depoimentos abaixo:

Porque você acaba se relacionando mais com o paciente, interagindo mais com o paciente, então você acaba tendo o compromisso de ver, de fazer um bom trabalho, porque no final você quer ver o paciente bem. (E1)

É muito bom, você fica mais próximo do doente, digamos assim, você fica mais próximo. (E4)

O que para as enfermeiras e pacientes surge como um vínculo por vezes obrigatório e conflituoso, mas repleto de positividades, é uma necessidade de ambientes como o das unidades de terapia intensiva e faz parte de um processo de acolhimento e humanização, já que em alguns momentos as UTI são consideradas ambientes frios e desumanizados. ${ }^{13}$

Logo, pode-se inferir que esse estar próximo é bom para os dois lados desta relação, pois satisfaz as necessidades dos pacientes de cuidados especializados e constantes e lembra as enfermeiras que, apesar de toda a tecnologia e dos conhecimentos e procedimentos, é a relação humana que alicerça o fazer da enfermagem: lembra-lhes que do outro lado tem sempre uma pessoa, que sente, tem vontades e direitos.

Contudo, essa proximidade não deixa de ser benéfica às enfermeiras, no tocante às necessidades de realização do trabalho, pois facilita e propicia que o trabalho possa ser executado de forma a atender satisfatoriamente as necessidades das pessoas internadas na UTI. Fato ilustrado pelo depoimento que se segue:

Aproximação, quanto mais próximo do paciente você está, você vai minimizar o caráter dos riscos que você tem com o seu paciente; então, quanto mais próximo da terapia intensiva, indica que você tem uma aproximação muito grande [...] isso traz uma aproximação muito grande, e respostas muito rápidas, em qualquer momento de uma fibrilação, em qualquer momento de uma taquicardia, que aquele paciente está evoluindo, em qualquer momento você está próximo ao paciente; então, essa aproximação é muito interessante, traz respostas imediatas [...] essa aproximação que você tem com ele e que te permite uma resposta imediata, te permite uma ação imediata, minimizando riscos de morte, minimizando risco, qualquer tipo de risco que possa vir a esse paciente [...] É sempre estar no box, é estar perto, no leito do paciente, ao alcance de suas mãos; então, qualquer intervenção, qualquer alarme que vai estar soando por causa de uma hipotensão, o alarme que vai está soando por uma taquicardia, uma fibrilação que o paciente está apresentando, isso você está com uma ação imediata ali. (E6) 


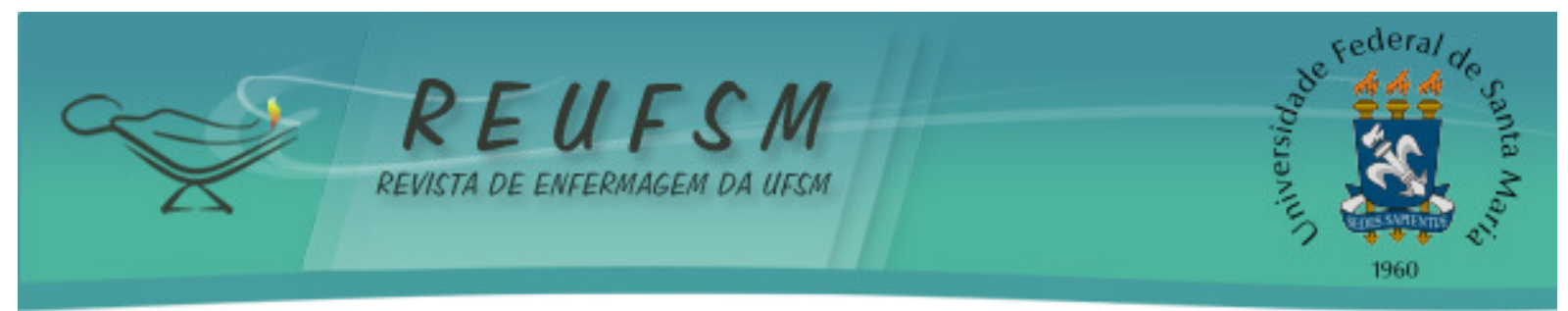

No compilar da análise, o estar próximo de seus pacientes no cotidiano da unidade de terapia intensiva é formadora da Práxis de ser enfermeira no cotidiano da UTI de forma quase inegável, seja pelos laços socioafetivos criados no conviver desse cotidiano, seja pelas necessidades dos pacientes em serem cuidados ou das enfermeiras de estarem sempre se lembrando de que sua contraparte é um ser humano, pela possibilidade de assistirem essas pessoas de forma condizente com suas necessidades. Assim, o estar próximo, apesar de presente ao longo dos anos do estabelecimento da enfermagem como profissão, não foi esquecido e, muito menos, perdeu a importância que, talvez, tivesse nos primeiros momentos da enfermagem.

\section{CONSIDERAÇÕES FINAIS}

A construção de uma Práxis sob o olhar aqui adotado não é linear e muito menos previsivel, pois se torna algo pessoal; trata-se dos significados que cada profissional atribui ao seu trabalho. Mas nem por isso deixa de ser importante, pois essas significações advêm do viver concreto e real das situações cotidianas dos profissionais.

Sendo assim, embasada na realidade, no que realmente é o viver cotidiano de uma unidade de terapia intensiva, as significações se configuram como elemento de fidedignidade para o embasamento de subsídios capazes de serem aplicados em muitos momentos da vida de um profissional de enfermagem.

É capaz de subsidiar uma formação mais adequada aos contextos reais de atuação, um aperfeiçoamento mais próximo da realidade vivida dentro da UTI, uma adequação de suas condutas frente às necessidades do cotidiano, além de ser uma forma de adequar este ambiente, a UTI, de forma a torná-lo mais aprazível tanto aos profissionais quanto às pessoas ali internadas.

Dentro desse ambiente, vivendo o cotidiano de uma unidade de terapia intensiva, os enfermeiros e enfermeiras conseguem resgatar e resignificar elementos que são inerentes ao nascimento da enfermagem, sendo que esse resgate não é meramente ilusório ou saudosista: ele é verdadeiro e aplicável, tem significado e relevância para esses profissionais.

É devido a isso que na formação da Práxis de ser enfermeira no cotidiano da UTI o trabalho em equipe surge como pilar de sustentação, porque realmente esses profissionais vêem no trabalho conjunto uma forma de expressar suas socialidades, de fazer bem suas funções, de poder sanar as necessidades dos pacientes, mesmo que não sejam de sua competência, porque reconhecem a importância de outros profissionais.

Por meio do trabalho em conjunto que as enfermeiras e enfermeiros conseguem (seja dentro da equipe de enfermagem, seja inseridos em uma estafe multiprofissional) expressar todos os seus conhecimentos, suas capacidades e potencialidades - e, assim, mostrar o seu valor e sua importância dentro do ambiente da unidade de terapia intensiva.

Da mesma forma, a proximidade com os pacientes sob seus cuidados também está no cerne do estabelecimento da enfermagem como profissão, e esses pacientes constituem-se no foco de trabalho da enfermagem e de seus profissionais. Assim sendo, assumem papel de destaque nos significados atribuídos por esses profissionais a suas práticas cotidianas.

É por esta proximidade que as enfermeiras conseguem visualizar os frutos de todo o trabalho, de todo o empenho que essas profissionais dedicam aos pacientes que necessitam estar internados em uma UTI, bem como estar em contato direto e próximo com esses pacientes de forma a poder desenvolver intensivamente suas práticas.

Assim, ainda hoje, apesar de todos os avanços, aparelhos e técnicas, os elementos humanos têm grande relevância nas práticas do ser enfermeiro no cotidiano da UTI. E, esta importância reflete-se na práxis de ser enfermeiro no cotidiano da unidade de terapia intensiva, mostrando que é pelo humano e pelo orgânico que os profissionais de enfermagem (devem e) se preocupam. 


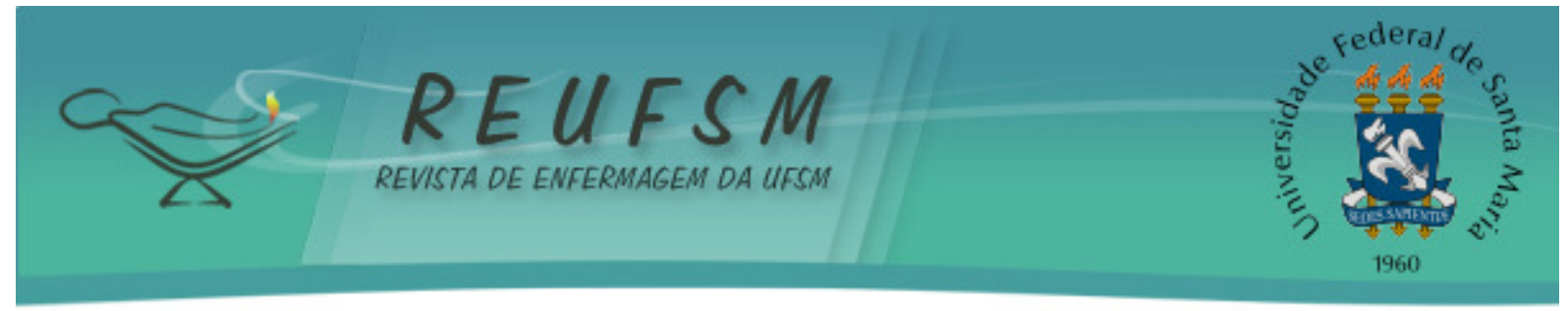

\section{REFERÊNCIAS}

1. Martins JT, Robazzi MLC. Nurses' work in intensive care units: feelings of suffering. Rev Latinoam Enferm. 2009 fev;17(1):52-8.

2. Campos JF, David HSL. Avaliação do contexto de trabalho em terapia intensiva sob o olhar da psicodinâmica do trabalho. Rev Esc Enferm USP. 2011 abr;45(2):363-8.

3. Favarin SP, Camponogara S. Perfil dos pacientes internados na unidade de terapia intensiva adulto de um hospital universitário. Rev Enferm UFSM. 2012 ago [acesso em 20/06/2014];2(2):3209. Disponível em: http://cascavel.ufsm.br/revistas/ojs2.2.2/index.php/reufsm/article/view/5178/3913.

4. Vargas AO, Ramos FRS. Autonomia na unidade de terapia intensiva: comecemos por cuidar de nós. Rev Bras Enferm. 2010 dez;63(6):956-63.

5. Scremin MPP, Prado ML, Schmidt RK. Por uma práxis de enfermagem criativa e reflexiva. Cienc Enferm. 2006 dez;12(2):15-22.

6. Vale EG, Pagliuca LMF, Quirino RHR. Saberes e práxis em enfermagem. Esc Anna Nery Rev Enferm. 2009 mar;13(1):174-80.

7. Kosik K. Dialética do concreto. 2ª ed. Rio de Janeiro (RJ): Paz e Terra; 1995.

8. Richter LM. Clássico marxista: "Dialética do concreto" (resenha). Rev Educação Políticas em Debate. 2012 jan-jul;1(1):236-48.

9. Maffesoli M. Elogio da razão sensível. 4ª ed. Petrópolis (RJ): Vozes; 2008.

10. Minayo MCS. O desafio do conhecimento: pesquisa qualitativa em saúde. 12a ed. São Paulo (SP): Hucitec; 2010.

11. Gibbs G. Análise de dados qualitativos. Traduzido por Costa RC. Porto Alegre (RS): Artmed; 2009.

12. Martins JT, Robazzi MLC, Marziale MHP, Garanhani ML, Haddad MCL. Significados do gerenciamento de unidade de terapia intensiva para o enfermeiro. Rev Gaúch Enferm. 2009 mar;30(1):113-9.

13. Maestri E, Nascimento ERP, Bertoncello KCG, Martins JJ. Evaluación de las estrategias de recepción en la Unidad de Terapia Intensiva. Rev Esc Enferm USP. 2012 fev;46(1):75-81.

Data de recebimento: 29/05/2013

Data de aceite: 17/01/2014

Contato com autor responsável: Gustavo de Mello Duarte

Endereço postal: Rua Dr Luiz Antonio Vieira Pena n56, São Mateus, Juiz de Fora, Minas

Gerais. CEP 36026-300

E-mail: enfergustaduarte@gmail.com 